\title{
Grow in Hone: Research on the Ideological Status of College Students during COVID-19
}

\section{- Based on the Empirical Analysis of the Data of 351 Colleges and Universities Nationwide in the Spring of 2020}

\author{
Xin Xu \\ Tiangong University, Tianjin, China \\ Email: 14423471@qq.com
}

How to cite this paper: $\mathrm{Xu}, \mathrm{X}$. (2020). Grow in Hone: Research on the Ideological Status of College Students during COVID19. Creative Education, 11, 2767-2771. https://doi.org/10.4236/ce.2020.1112202

Received: November 18, 2020 Accepted: December 20, 2020

Published: December 23, 2020

Copyright $\odot 2020$ by author(s) and Scientific Research Publishing Inc. This work is licensed under the Creative Commons Attribution International License (CC BY 4.0).

http://creativecommons.org/licenses/by/4.0/

\begin{abstract}
Based on empirical research and detailed analysis of technology, this article summarizes the ideological situation of college students during the epidemic: proactive, diverse forms of voluntary service, high attention to philosophical issues and national issues. Based on this, some suggestions for the reform and innovation of ideological and political theory courses are put forward.
\end{abstract}

\section{Keywords \\ College Students, Epidemic, Ideological Situation, Research}

\section{Origin}

In the spring of 2020, the sudden outbreak of COVID-19 disrupted the rhythm of people's life and forced most Chinese universities to adopt the online teaching mode to ensure the "suspension of classes", and the study and life of college students changed accordingly. Outbreak is test paper, it is a magnifying glass, in the face of sudden major public events, after major outbreaks hone, college students' ideological and political status, especially their value judgment, it's the ideological and political workers need to understand, therefore, conducted the research, the author led to on the basis of empirical depict college students during the outbreak (especially in January 2020 to June, hereinafter the same) portraits of ideological and political status, analysis of the causes, it provides scientific suggestions for teaching innovation and course construction in the future.

\section{Research Object}

The research objects are undergraduate and junior college students in domestic 
universities. From April to June 2020, a total of 3000 questionnaires were distributed through the network, including 2216 valid questionnaires. In June 2020, the research team selected 100 volunteers as interviewees and made follow-up in-depth telephone interviews, totaling about 3000 minutes, which made research more deeply and increased reliability research. The questionnaire and interviewees covered all provinces, cities and autonomous regions except Taiwan and Macao, involving 351 universities nationwide. Therefore, it was of universal significance for studying the ideological and political status of college students during the epidemic period.

\section{Research Methods}

The research group used a combination of questionnaire and interview to conduct research, and self-compiled the "Growing up in Hone-Research on the Ideological and Political Status of College Students during the Epidemic" questionnaire and "Growing Up in Hone-Research on the Ideological and political Status of College Students during the Epidemic" interview outline. The outline of questionnaire and interview were set up with reference to the relevant papers on the study of ideological and politics during the epidemic, solicit the opinions of ideological and political theory course teaching and the scientific research experts and scholars, from college students during the epidemic of "concern about the affairs of state", "philosophical thinking about the problems", "volunteer service to participate in" three aspects set up 25 questions. Before the questionnaire was released, some experts and undergraduates were invited to make prediction tests and modifications, and the final draft was made on this basis.

\section{Data Analysis and Conclusions}

1) Contemporary college students are highly proactive and involved in ideological and political topics during the epidemic.

Set up a questionnaire "would you like to leave your contact information, we will follow-up in-depth interview" option, 2216 interviewees, there are 776 (including 630 real-name) left behind the contact method, according to their province, we selected 100 volunteers to do deep interviews, respondents are very cooperative, which accumulated nearly 3000 minutes of the interview data. This shows that contemporary college students are willing to discuss their own political and ideological situation in the epidemic situation, which is in contrast to the apathy and low attendance rate of ideological and political theory courses in the past. It shows that after experiencing the major epidemic, college students have increased their interest in ideology and politics, have obvious awareness of personal ideological and political changes, their active share and discuss willing in the interview has proved this point.

2) High participation and initiative in volunteer service, various forms of volunteer service

The investigation of the respondents who participate in volunteer services during the epidemic prevention and control period, there are 17 percent participated 
in volunteer services. According to the "China Volunteer Service Network", the total number of real-name volunteers in China is 173 million, accounting for $12.3 \%$ of the country's total population. It can be seen that the proportion of volunteers participating in epidemic prevention and control among college students is higher than that among the whole population.

In the survey of what kind of volunteer services volunteers participate in, the vast majority of volunteers participate in community prevention and control, publicity of epidemic prevention knowledge, 17.2 percent of volunteers to teach, 18 percent of volunteers have engaged in the production of anti-epidemic materials. Some volunteers, while participating in the anti-epidemic activities at the same time to donate their own initiative just won the scholarship last semester. This shows that contemporary college students are active in taking part in the epidemic prevention and have made their own contribution to the fight against the epidemic.

In the survey, the reasons for participating in volunteer activities, "personal responsibility" and "mission" accounted for 70 percent and 54 percent. On the one hand, it shows that college students have strong personal independence and value judgment. On the other hand, it also shows that the college students' personal value orientation is highly consistent with the mainstream value orientation of the country in their volunteer service against the epidemic.

3) High concern on philosophical issues

During the design of the questionnaire, the author set up a group of projects concerning college students' attention to philosophical issues during the epidemic: "The meaning of life during the epidemic", "The relationship between human and nature during the epidemic", "The bottom line thinking during the epidemic". According to the survey results, about $40 \%$ of the respondents expressed "very concern" about the three groups of questions, and about $50 \%$ expressed "relatively concern", which was a huge contrast with the indifference of college students to philosophical issues in our impression. The reason is that the epidemic broke the track of daily life, everyone suddenly faced with the problem of life and death, breaking the individual's habitual thinking, stimulating students' Thinking on the ultimate problem. For the "relationship between man and nature" thinking, is mainly due to the huge spread of the virus and lethality, broke the normalized centered on human world life, highlights the human as part of a natural biological chain of ordinary sex, causing students to think about the relationship between man and nature. The reason for thinking about "bottom line thinking" is that General Secretary Xi Jinping successfully applied the basic principles of Marxism in the deployment and prevention and control of the epidemic, especially mentioned the bottom line thinking. During the special period of the epidemic, it played a great role in making college students realize the importance and effectiveness of Marxist theory, thus arousing their interest.

4) High attention to national issues

When the author designed the questionnaire, he set up a group of feedback about the state affairs during the college students' epidemic. We can see that the 
respondents' answers to the three questions "has your self-confidence in Chinese culture been enhanced", "has your self-confidence in the socialist system been enhanced" and "has your recognition of the Chinese Communist Party been enhanced" in the national anti-epidemic performance are highly consistent. About $75 \%$ of the respondents' answers have been greatly improved, while about $20 \%$ of the respondents' answers have been slightly improved. In other words, about 95\% of the college students' evaluation of Chinese culture, the socialist system and the Chinese Communist Party is very positive because of the country's anti-epidemic performance. This fully shows that our party and country have won high recognition from the masses of the people, especially contemporary students, in the fight against the epidemic. For them, this is not only a test, but also a baptism and sublimation of thought.

\section{Suggestions on the Teaching of Ideological and Political Courses Based on Investigation Results}

1) Closely follow the students' ideological trends, resonate with them, tell stories about the epidemic, and innovate the teaching of ideological and political courses.

Education is the knowledge of shaping people, and the ideological and political course puts moral education in the first place, aiming at guiding students to establish correct three views (Xi, 2020). In order to achieve this goal, it is necessary to establish deep resonance with students' emotions and values, so as to achieve the unity of knowledge transfer and values shaping. However, in the past teaching, it is difficult for teachers and students to resonate with each other at the same frequency, and even teachers are full of emotions while students are indifferent. In order to arouse students' enthusiasm and guide them into a common "field", many teachers use modern teaching methods to carry out "situational teaching". In this epidemic, teachers and students are virtually in a situation with the background of fighting against the epidemic. Under this background, the author thinks that we should conform to the characteristics of young students, choose the things around us, the things of our peers, and take the small cases as the principle, and use the combination of teachers' guidance, comments and students' stories to tell the story of fighting against the epidemic.

2) Focus on social hot spots, respond to student doubts, and enhance the appeal of ideological and political classrooms.

Marxist theory is not a theory in the study, practicality is a clear sign of Marxism (Mao, 1991). A strong response and answer to the problems of the times is the theoretical charm of Marxism. In the face of the new crown epidemic, why the United States, known as the world's number one power, is vulnerable to the epidemic, while China can quickly and effectively contain the deterioration of the epidemic and resume work and production as soon as possible. If teachers can use this question as an entry point, they can analyze the political system, cultural background, economic system, etc., and use comparative methods to 
expose the anti-people nature of the capitalist system, and provide students with knowledge and understanding while answering questions. Transmission of values.

3) Pay attention to voluntary activities and enhance the consciousness of action under the theory.

It is one of the highlights that College Student actively participates in anti-epidemic service and it is also the practice of theory. The voluntary service of college students in the epidemic situation reflects spontaneity, initiative and expertise. It interprets the essence of volunteer service that we are active to take part in the volunteer position when country and the people in need. In the future course teaching, we should integrate the strengthening of volunteer spirit and ideological and political teaching, encourage students to practice Marxism and socialist core values in life, and give appropriate extra points in the final examination. Combining students' majors with ideological and political theory teaching and volunteer service, we should creatively carry out practical teaching with specialty as the feature, volunteer service as the carrier, and ideological and political theory teaching as a bridge, so as to make practical teaching blossom and make actual effects. Knowledge.

And action should go hand in hand.

4) Innovating thinking, theoretical charm, improving students' ability of thinking.

Theoretical property is the characteristic of Ideological and political theory course, but the abstract theory makes many students flinch (Xi, 2017). In order to increase the attraction and activity of the class, many teachers innovate the way of teaching and make the theory popular and easy to understand. However, the further charm of Marxist theory only relies on emotional rendering is far from enough. What is need is an in-depth interpretation of the theory. During the epidemic period, students' interest in philosophical issues has increased. Teachers should take this opportunity to guide students to learn the original works and study theories in combination with contemporary problems based on Marx's classic works, so as to improve their speculative ability and theoretical level.

\section{Conflicts of Interest}

The author declares no conflicts of interest regarding the publication of this paper.

\section{References}

Mao, Z. D. (1991). Selected Works of Mao Zedong. Beijing: People’s Publishing House, Volume 1, 287-288.

Xi, J. P. (2017). Xi Jinping on State Administration. Beijing: Foreign Languages Publishing House, 342.

Xi, J. P. (2020). General Secretary Xi Jinping's Important Statements on Education. Beijing: Higher Education Press, 210. 